\title{
Colombia y la instrumentalización de la pandemia de covid-19*
}

\author{
Colombia and the instrumentalization \\ of the covid-19 pandemic
}

\section{Jorge Márquez- Valderrama ${ }^{i}$ \\ i Profesor titular, Facultad de Ciencias Humanas y Económicas/Universidad Nacional de Colombia. Medellín-Colombia orcid.org/0000-0002-9677-3619 jmarquez@unal.edu.co}

Recebido em 1 out. 2020. Aprovado em 9 feb. 2021.

\begin{abstract}
MÁRQUEZ-VALDERRAMA, Jorge. Colombia y la instrumentalización de la pandemia de covid-19. História, Ciências, Saúde - Manguinhos, Rio de Janeiro, v.29, n.1, jan.-mar. 2022, p.261-267.
\end{abstract}

\section{Resumen}

Más allá de las diferentes formas de sufrimiento derivadas de la pandemia de covid-19, en Colombia se ha gestado un escenario de instrumentalización de los acontecimientos en las esferas empresarial, educativa y gubernamental. Aunque la cuarentena obligatoria fue la medida de contención preponderante, supuso una doble percepción desde la perspectiva de los ciudadanos de escasos ingresos: la disyuntiva "morir de hambre o de coronavirus". Desde esas esferas se consideró la pandemia como el momento oportuno para establecer y alcanzar nuevos objetivos: fomento de la educación virtual, creación de nuevos emprendimientos, apertura de nuevos mercados y malversación del erario público.

Palabras clave: Colombia; instrumentalización; pandemia; covid-19.

\section{Abstract \\ In addition to the different forms of suffering caused by the covid-19 pandemic, a scenario emerged in Colombia in which business, educational and government spheres instrumentalized events. Although mandatory quarantine was the most widely-used method of containment, from the point of view of low-income citizens, it was perceived as a duality, the dilemma of "dying of hunger or coronavirus." Business, education and government sectors, however, saw the pandemic as an opportunity to establish and achieve new goals: encouraging virtual education, creating new enterprises, opening up new markets and misappropriating public funds.}

Keywords: Colombia; instrumentalization; pandemic; covid-19. 
$\mathrm{L}$ a mortalidad por covid-19 ha sido mucho menor en países que, antes de la pandemia, habían actualizado y adecuado sus sistemas de salud, adoptado medidas preventivas y acondicionado los espacios de las unidades de cuidados intensivos para contar con equipos idóneos, de manera que los profesionales de la salud pudieran ejercer su trabajo de manera eficaz, por ejemplo, Alemania y Corea del Sur. Sin embargo, en países como Italia, España, Inglaterra y EEUU, la parsimonia en la prevención y contención tuvieron como consecuencia el aumento inusitado del número de contagios y de muertos.

Debido a que, en 2020, la pandemia en América Latina se manifestó con retraso respecto a varios países europeos y asiáticos, y al observar la acelerada propagación del virus, en algunas ciudades de la región las autoridades evaluaron tempranamente la eficacia de las medidas preventivas adoptadas por otros países para limitar y bloquear el contagio. En Colombia, al prever las repercusiones económicas y sanitarias de un posible brote y considerando la penuria en infraestructura y en personal médico para atender a los contagiados, algunos mandatarios locales iniciaron campañas de información acerca de la transmisión del virus SARS-CoV-2, incluso antes de que se manifestara el primer caso, anunciado el 6 de marzo.

Desde el 23 de marzo de 2020, la cuarentena y las medidas de aislamiento fueron respetadas en el ámbito nacional, pero a comienzos de junio, por presiones de los gremios comerciales, el gobierno nacional flexibilizó las medidas sanitarias, anunció mensajes triunfalistas a la población y produjo confusión respecto a las medidas de aislamiento. En ese momento apareció la llamada "cuarentena a la carta" ridiculizada en redes sociales. Incluso se decretó la apertura de centros comerciales para hacer efectiva una medida fiscal demagógica prometida meses atrás: permitir tres días del año de ventas sin impuesto de valor agregado en productos como los electrodomésticos importados. Esos tres días fueron precisamente fijados como viernes en plena cuarentena, llamados sarcásticamente "covidfriday", acontecimiento que aumentó las cifras de contagios desde el 19 de junio de 2020.

Con respecto a la pandemia, el gobierno colombiano se ha caracterizado sobre todo por aprovecharla en favor de los grandes grupos económicos y del sector financiero, mientras que la población general ha quedado librada a su propia suerte en un confinamiento imposible de cumplir sin apoyo ni protección. Los sectores sociales con escasez de recursos económicos se han encontrado en una encrucijada en la cual se debe elegir el camino menos corto a la muerte. Es ilustrativo el fenómeno de los trapos rojos en Colombia, colgados en las entradas, ventanas y balcones de las viviendas. Se trata de una manifestación representativa de la disyuntiva entre "morir de hambre" o "morir de coronavirus". El gobierno nacional restringe mediante cuarentena y toques de queda mucha parte de la actividad comercial, lo que hace muchas personas que viven el día a día y dependen de la economía informal vean muy limitadas sus fuentes de sustento. $Y$ aunque al comienzo de la pandemia (marzoabril de 2020) en algunas ciudades se respetaron las medidas de cuarentena, en los sectores populares la infracción de las normas ha sido una expresión del escepticismo colectivo y de la resistencia a que la pandemia interrumpa las actividades informales de sustento diario.

La actitud tradicional de los gobiernos colombianos, de desprecio hacia la opinión de los científicos, se ha acentuado en el siglo XXI, cuando el neoliberalismo se convirtió en la lógica orientadora de la vida. Muestra de ello es el endeble "gasto en investigación y 
desarrollo" de Colombia con respecto a su PIB (el dato más reciente del Banco Mundial, 2018, es 0,237\%). Esta enjuta inversión ha caracterizado el devenir del país, pero también es indicio de la indiferencia de las élites respecto a la educación y a la investigación, y al bienestar que aportarían a las comunidades.

Mientras que el gobierno nacional adoptó la medida de la cuarentena, más por presión de mandatarios locales que por propia iniciativa, varios expertos en epidemiología y salud pública - por ejemplo, Mario Hernández, coordinador del doctorado de Salud Pública de la Universidad Nacional de Colombia; Hernando Nieto, expresidente de la Asociación Colombiana de Salud Pública; César Burgos, presidente de la Asociación Colombiana de Sociedades Científicas (Hernández, Restrepo, 20 mayo 2020) - aprobaron el aislamiento preventivo general y las medidas de descontaminación permanente como estrategia para disminuir las pérdidas de vidas. Ponderaron esas medidas como el medio para evitar el colapso del deficiente sistema de salud colombiano, caracterizado por la reducción de su presupuesto aunado a una delegación en las administraciones locales de la responsabilidad social con los más vulnerables. La precariedad de los servicios de salud y su privatización (iniciada por la ley 100 de 1993) constituyen la dificultad estructural para la atención, no sólo de los casos urgentes de covid-19, sino también de otras enfermedades. A finales de enero de 2021, la improvisación gubernamental continúa y mientras siete países de América Latina ya comenzaron a vacunar a su población, en Colombia hay incertidumbre total y serias dudas (presunta corrupción) sobre los contratos con alguna firma extranjera para proveer las vacunas al país.

\section{Instrumentalizar una epidemia}

Con motivo de la pandemia, ciertos esquemas acerca de la biopolítica la ubican del lado de las nociones y discursos de la negatividad. Así, el modelo biopolítico, "negativo", correspondería a las sociedades disciplinares y se expresa mediante metáforas belicistas y de intrusión. El poder disciplinar se ejerce sobre lo somático y ese principio de negatividad se evidencia, por ejemplo, en la biopolítica de la cuarentena. Por contraste, habría un modelo psicopolítico, "positivo", heredero de los discursos del management y de la psicología positiva que se han consolidado, desde los años 1950 (Han, 2014), como técnica de poder más eficiente y adecuada para valorar la experiencia social e individual en las sociedades de la autonomía (Ehrenberg, 2010). El principio de la positividad, característico de las sociedades del rendimiento, neoliberales, se ha instalado socialmente como la forma óptima de valorar los padecimientos, sobre todo los relacionados con el malestar psíquico.

No obstante, esta disyunción entre biopolítica y psicopolítica no se ha traducido en un desplazamiento diacrónico de un modelo hacia el otro. Hoy ambos coexisten, como es evidente en el reforzamiento del positivismo de la "salud mental" en plena emergencia viral y epidémica por covid-19 y en las medidas biopolíticas de aislamiento y distanciamiento físico adoptadas por numerosos gobiernos. Aunque la nueva pandemia puso a trastabillar este esquema dual, él permite iniciar la reflexión sobre la instrumentalización de las epidemias y en especial de la actual, tomando como país de referencia Colombia.

Es fácil enumerar acontecimientos que constituyen la coyuntura social derivada de la propagación del virus: distanciamiento físico llamado "distanciamiento social" porque 
limita las oportunidades de socialización en espacios públicos; restricción en la enseñanza presencial; mediatización del miedo al contagio que causa sospecha y aversión al contacto con el otro; generalización mundial del uso en público de mascarillas, incertidumbre frente al retorno al uso de los espacios públicos, a la economía derivada de la vida nocturna y al consumo callejero. Se podrían detectar más acontecimientos como índices de cambios en la vida cotidiana, pero resumiendo, con la epidemia estamos ante una coyuntura que irrumpe limitando los lazos sociales y confinando la cotidianidad. Sin embargo, desde diferentes esferas (gubernamental, empresarial, individual, religiosa) se ha enunciado y promovido una concepción positiva de la instrumentalización de las circunstancias e incluso de las contingencias ligadas a este contagio.

La concepción positiva de la instrumentalización de la pandemia corresponde a valoraciones del conjunto de circunstancias sociales que ella produce en cada contexto espaciotemporal como oportunidades para el beneficio en cada una de las esferas de la vida social e individual. En efecto, una de las reacciones colectivas frente a las consecuencias de la covid-19 ha sido buscar y ponderar el impacto positivo del nefasto acontecimiento. Esto se expresa desde las técnicas del coaching y el management como: "De las crisis surgen nuevas oportunidades". Hoy se enuncia esta máxima en múltiples facetas: ecológica (la Tierra descansa y se recupera); financiera (una oportunidad para invertir en sectores de primera necesidad); cotidiana (más tiempo para mí o mayor tiempo en familia); educativa (hay que acelerar el aprendizaje y la adopción de los procedimientos de virtualización).

Esta valoración difiere de las concepciones negativas de la instrumentalización de la epidemia, ya sea en su forma de valoración peyorativa del acto mismo de instrumentalizar o de la enunciada por discursos conspirativos que señalan a gobiernos, grandes industrias o individuos de enormes ingresos al volverse artífices de circunstancias sociales y mediáticas que actúan como tácticas para el beneficio de intereses particulares. Se cree en una especie de complot que favorece a unos pocos y conlleva efectos funestos para la mayoría. Estos discursos se basan en especulaciones sobre los resultados contingentes de la epidemia: cambios en los polos del poder global, aumento de la desigualdad económica y radicalización de la vigilancia y el control social.

Sin embargo, para pensar la instrumentalización de las epidemias, en lugar de tomar alguna opción negativa o positiva, se puede partir del concepto propuesto por el filósofo alemán Max Horkheimer (1973, p.7) acerca de la razón instrumental expresado en su obra Crítica de la razón instrumental, "la verdadera esencia de la razón consiste en hallar medios para lograr objetivos propuestos en cada caso". Desde este punto de vista, no todas las acciones para instrumentalizar algo se pueden valorar desde una concepción dicotómica. Un concepto amplio, no polarizado, de instrumentalización nos permite comenzar por tomar distancia respecto de los usos sociales, políticos, económicos, religiosos e individuales que se le pueden dar a una epidemia. Es posible no decantarse por el discurso condenatorio o por el fundamentado en la lógica del beneficio e intentar comprender de manera sociológica, filosófica e histórica en qué consiste la instrumentalización de las epidemias ya que, contrario a las especulaciones de los conspirativistas, sí tenemos evidencia empírica que sustenta nuestra hipótesis que afirma que, en efecto, en Colombia se ha instrumentalizado la emergencia viral por covid-19. Varios ejemplos ilustran esto. 


\section{En la esfera empresarial}

En contraste con el momento anterior a la llegada de la covid-19 y la aplicación de las medidas preventivas y de contención, uno de los efectos de la cuarentena obligatoria generalizada ha sido la disminución de las ganancias de diversas empresas e industrias.

A pesar de las estrategias financieras adoptadas en Colombia (créditos y congelación de deudas a empresarios y sector financiero), la cifra de desempleo se incrementó en el mes de mayo de 2020 en un 21,4\% (DANE, 31 mar. 2020). La disminución de los niveles de producción y de consumo debido al confinamiento causó el cierre de numerosas pequeñas y medianas empresas, muy dependientes del contacto directo con los clientes y proveedores y que, además, no lograron adaptar sus actividades comerciales a la virtualidad. Estas empresas tampoco pudieron proporcionar a sus empleados la remuneración que garantizara la subsistencia durante el confinamiento. Este panorama de pausa de las actividades productivas y recortes de personal provocó el incremento de la incertidumbre sobre la posición del empleado y la constante preocupación por el sustento diario que derivó en el incremento de los niveles de estrés, ansiedad y depresión.

Sin embargo, desde la esfera empresarial se ha promovido una concepción optimista de las consecuencias de la pandemia, y se ha instrumentalizado la coyuntura según la consigna: "una oportunidad para emprender, innovar, invertir y reinventar". Con esta concepción han emergido nuevos emprendimientos y varias empresas han modificado sus productos, sus formas de distribución y sus segmentos de mercado. Aunque numerosas pequeñas empresas fracasan, hay unas pocas que han aumentado su margen de ganancia (al igual que sus inversores) precisamente como consecuencia de la pandemia. ${ }^{1}$

\section{En la esfera educativa}

La medida de la cuarentena ha propiciado la expansión de la cibercultura en establecimientos que apenas la conocían o se resistían a ella. Esta ha sido concebida como la cultura surgida a partir del uso de las redes informáticas para la comunicación, el entretenimiento y el mercado electrónico. Sin embargo, un impacto de la pandemia y una consecuencia del confinamiento ha sido el incremento del uso de tecnologías de la información y la comunicación para realizar clases, conferencias y formalidades administrativas.

En la esfera educativa, en Colombia se optó por no suspender totalmente las actividades y usar las posibilidades de la comunicación remota en tiempo real y en interacción asincrónica. Las directivas de universidades predican que la pandemia y el confinamiento permiten que le demos una oportunidad a la "experiencia digital", que lo que imaginábamos como el porvenir de las formas de enseñanza-aprendizaje se ha puesto en marcha; es el momento de acelerar los procesos de digitalización y mediación educativa a través de plataformas virtuales.

Esto supone un imperativo de adaptación para la generación de quienes no son "nativos digitales", para quienes aún se resisten a la mediación de plataformas virtuales en la educación; pero también supone una nueva forma de exclusión que afecta a quienes 
no cuentan con una conectividad permanente, ya sea por no disponer del equipamiento adecuado, por el alto costo de internet en Colombia o porque este servicio no se presta en condiciones óptimas en todas las regiones.

\section{En la esfera política}

Con motivo de la pandemia se han dado en Colombia varios casos de malversación de recursos públicos destinados a la ayuda de las personas económicamente más vulnerables (aún más en condiciones de confinamiento obligatorio). Esto puede leerse como una instrumentalización de la pandemia; no que la pandemia propicie la corrupción, pues este fenómeno está muy arraigado en la sociedad colombiana, sino más bien que la situación de emergencia ha hecho movilizar recursos que de otra manera no se habrían desbloqueado y el abuso de posiciones de poder los ha desviado de forma fraudulenta o los ha restringido a intereses particulares de ciertos grupos en una sociedad desigual y altamente polarizada. Los políticos de turno han aprovechado la coyuntura para distribuir sesgadamente las ayudas a través de redes clientelistas que ellos mismos habían establecido en las últimas elecciones regionales (2019).

En el nivel nacional la situación de emergencia ha otorgado amplias facultades al Poder Ejecutivo, lo que ha aprovechado el presidente Iván Duque para gobernar mediante decretos, sin vigilancia de otras instancias políticas: una especie de estado de excepción que favorece la corrupción. El recientemente creado Ministerio de Ciencia, Tecnología e Innovación (ley 1951 de 2019 que convirtió a Colciencias en un ministerio) anunció el 25 de marzo una batería de medidas para hacer frente a la pandemia. La más polémica fue la "Mincienciatón", una convocatoria dotada de unos 7 millones de dólares para investigadores que deben desarrollar, entre otros, dispositivos médicos o sistemas de monitoreo en tiempo real para hacer seguimiento a la pandemia (La Liga Contra el Silencio, 13 mayo 2020). No se surtieron los protocolos normales en este tipo de convocatorias. Además, en julio de este año el gobierno aprovechó para cambiar casi todo el personal de lo que era Colciencias, y así pagar favores con cargos a políticos simpatizantes del partido de gobierno.

\section{A manera de cierre}

A comienzos de 2021, tres hechos marcan la situación de la pandemia en Colombia. Uno: el aumento acelerado de ocupación de unidades de cuidados intensivos en las principales ciudades. Dos: el crecimiento del número de personas infectadas que ha alcanzado cifras récord, con respecto a los 12 meses de la pandemia. Tres: el atraso del gobierno de Colombia para iniciar algún plan de vacunación, aspecto en el cual la incertidumbre es total.

A pesar de esta realidad, la política gubernamental sigue caracterizada por la improvisación, la corrupción y la desinformación. Se echa mano, a veces, de medidas biopolíticas (toque de queda, cuarentena, pico y cédula), y otras veces se recurre al discurso de la psicopolítica (resiliencia, autocuidado, automotivación). Sin embargo, lo disciplinario y lo optimizador se dirigen de manera desigual a la población, según medidas erráticas e inopinadas. 
Por otro lado, la pandemia se sigue utilizando con fines particulares mediante el gobierno por decreto, que sigue favoreciendo al gran capital, a los sistemas financieros y a cierta "clientela" del partido de gobierno de turno. En ausencia de una política sanitaria clara, que tenga en cuenta al conjunto de la población, continúa la desaceleración económica, el aumento de muertes por covid-19 (unas cuatrocientas por día), el desprecio oficial frente al estamento científico y la incertidumbre total en la economía y en la educación.

\section{AGRADECIMIENTOS}

Este texto se deriva de las discusiones del seminario "Tiempo de epidemias en las sociedades de individuos", coordinado por Jorge Márquez entre el 29 de abril al 24 de junio 2020, como actividad del grupo Producción, Circulación y Apropiación de Saberes PROCIRCAS de la Universidad Nacional de Colombia, sede Medellín. Nuestra gratitud a Cristian Camilo Rojas Obando, estudiante del Programa de Ciencia Política de la FCHE, quien recogió y organizó en un primer borrador coherente gran parte de los comentarios y preguntas del seminario.

\section{NOTAS}

* El siguiente texto es una versión más completa, actualizada y sometida a revisión de pares de un post que apareció en el blog de História, Ciências, Saúde - Manguinhos.

${ }^{1}$ Los datos de finales de 2020 son pavorosos: en el último trimestre de 2019 y el primero de 2020, el número mensual de solicitudes de insolvencia de las empresas ante la Superintendencia de Sociedades de Colombia era de 70. En el tercer trimestre de 2020 se llegó a 120 solicitudes mensuales y no cesa de aumentar.

\section{REFERENCIAS}

DANE, Departamento Administrativo Nacional de Estadística. Mercado laboral, 31 mar. 2020. Disponible en: https://www.dane.gov.co/index. php/estadisticas-por-tema/mercado-laboral/ empleo-y-desempleo. Acceso en: 11 jul. 2020.

EHRENBERG, Alain. La société du malaise. Paris: Odile Jacob, 2010.

HAN, Byung Chun. Psicopolítica: neoliberalismo y nuevas técnicas de poder. Barcelona: Herder, 2014.

HERNÁNDEZ, Mario; RESTREPO, Darío. Covid-19 y salud: mutar para vivir. $U N$ Periódico, 20 mayo 2020. Disponible en: http://unperiodico.unal.edu.co/pages/detail/ covid-19-y-salud-mutar-para-vivir. Acceso en: 20 de mayo de 2020.

HORKHEIMER, Max. Crítica de la razón instrumental. Buenos Aires: Editorial Sur, 1973.

LA LIGA CONTRA EL SILENCIO. Últimas noticias de un ministerio en emergencia, 13 mayo 2020. Disponible en: https:// ligacontraelsilencio.com/2020/05/13/ultimasnoticias-de-un-ministerio-en-estado-deemergencia. Acceso en: 6 dic. 2020.

\section{$\rightarrow \rightarrow \rightarrow<<<$}

